\title{
Introduction of a Research component in the undergraduate medical curriculum - Review of a trend
}

\author{
Sreedharan J
}

Professor of Biostatistics \& Assistant Director, Research Division, Gulf Medical University, Ajman, UAE

\section{Editorial}

\section{Corresponding Author:}

Dr. Jayadevan Sreedharan

Professor of Biostatistics \& Assistant Director

Research Division

Gulf Medical University, Ajman, UAE

Email : drjayadevans@gmail.com

\section{Introduction}

The question of whether a research component should be an integral part of medical curriculum has been debated in the past and is still controversial. Patient care is the most important aspect of a medical graduate but teaching, administration and research are also essential aspects. The implementation of a research component is more important at a student level as it helps to develop a judicious insight in their academic and clinical practice, which every medical person should possess. Evidence based medical practice ${ }^{1}$ is now receiving great emphasis internationally. Scholarly activity programmes are essential components of the modern undergraduate medical curriculum ${ }^{2}$. To make 'importing' knowledge to indigenous generation of knowledge it is important to develop research oriented educational programmes both at the undergraduate and postgraduate level ${ }^{3}$. In the past few decades, there is a trend of including research component in the undergraduate medical curriculum and this is shown to increase the interest of the students to conduct research after their graduation ${ }^{4}$. The changes of including the research component as curricular or extra-curricular component in undergraduate medical curriculum in many countries during the last few decades began in some of the universities in US and Europe. Many of the South Asian countries are going to start the change in the next few years. Thus there is an increasing trend of including research component in the medical curriculum over the years.

\section{Nature of the trend}

Many developed countries have introduced research programmes for medical students in recognition of the importance of imparting knowledge on how to conduct research in the medical curricula. In Case Western Reserve University School of Medicine (CWRU) in the US, a mandatory four months research block is included in the school curriculum. During this period, students work fulltime with a mentor identifying research questions, framing research methods, carrying out the research, conducting an analysis, and communicating their results in a write up $^{5}$. The University of California in US runs the University of California, San Diego (UCSD) Research Associate Program to incorporate undergraduates with emergency medicine research ${ }^{6}$. One of the urban medical schools in the US has made it mandatory for medical students to develop, design and implement a research project during their clinical years of study ${ }^{7}$. In the US, during the last decade, two large programmes that have sought to engage students in research are the National Institutes of Health (NIH) sponsored Medical Student Research Fellowship Programmes (MSRFs) and the Doris Duke Clinical Research Fellowship (CRF) Programme ${ }^{8-9}$.

School of Medicine and Dentistry in Queen's University, Belfast, introduced a new curriculum in the year 2005-2006, which included more research components to help students understand the principles underpinning scientific research ${ }^{4}$. University of Western Ontario, Canada introduced a rural summer studentship program with instructors in small communities. This program provides students the opportunity to perform rural health research combined with clinical learning ${ }^{10}$. A survey was conducted among second and fourth year undergraduate students of Queens University, University of Ottawa, and University of Western 
Ontario to assess their attitude towards research methodology, and their involvement in research projects as well as perceived barriers. It was observed that $83 \%$ agreed that some participation in research was likely valuable within their medical education. In the study only $15 \%$ of respondents felt that there was sufficient training in research methodology in medical school ${ }^{11}$.

In the Netherlands, students are required to do full-time individual research projects between years 4 and $6^{12}$. Research training is provided to all undergraduate students in the Leiden University Medical Center (LUMC) in Netherlands, where the critical appraisal of scientific reports is a core element in the curriculum. Students with above average academic ambitions are encouraged to participate in high level medical research projects and voluntary courses to develop their skills more. Students who are motivated, with good academic performance spend about $20 \%$ of their time on extra research ${ }^{13}$. All medical schools in South Africa expose their undergraduate students to research methodology and statistics training. Except in one university, all other universities it is a mandatory course ${ }^{14}$.

In Bangladesh, a research component is included in the medical curriculum. University of Gadjah Mada, Indonesia where integrated teaching is practiced, research has been incorporated as one of the components. In Sri Lanka, during phase two of the undergraduate curriculum community medicine, clerkship and research projects are included. Dedicated time for data collection and report writing is included in the curriculum ${ }^{15}$.

Research is not considered a part of the medical curriculum in many of the developing countries. In many South Asian countries, research component has not been made mandatory in the medical curriculum ${ }^{16}$. Studies report that some of the medical schools in India, Pakistan and Nepal also conduct research projects and community based epidemiological studies during their studentship and internship though it has not become an integral part of the medical curriculum ${ }^{16-18}$.

Even six decades after independence, medical research, which is the mother of new knowledge, has remained a non-issue in India and students rarely get a chance to acquire knowledge on research during their undergraduate course. Research methodology is not included as part of the medical curriculum ${ }^{3}$. One study in India reported that $91 \%$ of interns reported no research experience in their medical school $^{19}$. Experts opined that as the current medical curriculum is over burdened, instead of including research component in the medical curriculum, focus should be given to "strengthen the short term studentship" program for the students $^{20}$. Deo suggested that it is time that we thought of "research training" as an integral part of the MBBS curricula in India by introducing a short duration (one week) research-training programme as a regular part of MBBS syllabus. He also suggested that it should be conducted at the beginning of the internship so that students do not face additional examination burden. He emphasized that it would benefit those interested in research ${ }^{3}$. In India, a fair number of students are interested in research, which is evident from the increasing popularity of the ICMR Short Training Studentship (STS) programme ${ }^{21}$.

The current undergraduate academic programmes in Pakistan are not producing enough personnel for research purposes in the various medical fields. The main reason for this is the medieval curriculum which focuses on didactic learning. This curriculum does not motivate students' interests in research during their study in medical school and hence they are less likely to seek a research experience $^{22}$.

Undergraduate medical curricula in some of the medical schools in Nepal are community oriented, student-centered, self-directed and problem-based with integrated teaching and learning. Community-based learning is carried out in many medical schools in Nepal following its initiation at the Institute of Medicine, Kathmandu in $1978^{15,23-26}$.

Previously, the core curriculum of most of the medical schools in Malaysia was derived from traditional British system of medical education and tended to focus on three main themes that dictated teaching and learning; diagnosis and treatment, procedural and communication skills, and key advances in biomedical knowledge and technology. Over the last 20 years, the curricula of these medical schools became more integrated, interactive and community-oriented and included elements of research and evidence-based medicine ${ }^{27,28}$.

A study conducted in GCC countries (which included Saudi Arabia, Kuwait, Bahrain, Qutar, UAE, Oman and Yemen) among 30 medical colleges reported that in two colleges research methods are not included in the curriculum, in seven colleges it was a separate required course and in 10 colleges it was part of required course ${ }^{29}$. Students' research is an integral part of the undergraduate curriculum in the UAE University, University of Sharjah and Gulf Medical University in $\mathrm{UAE}^{30}$.

\section{Factors determining the trend}

First and foremost, student research is dependent on research activity at a regional and national level. Many factors determine the trend of introducing research component in the undergraduate medical curriculum. The main reason for this is the medieval curriculum which focuses on didactic learning. Good mentorship is a vital component of effective student research. Some faculty lack experience in research. Other problems reported are lack of time for meaningful research, routine studies and deterioration of skills in day to day clinical practice due to more time being spent on research activities and 
Introduction of a Research component in the undergraduate medical curriculum

inadequate faculty-student interaction ${ }^{11,22,31}$. The influence of research experiences is seen as a significant predictor of undergraduate students' participation in research ${ }^{32}$.

\section{Advantages and Disadvantages}

The nature of work even in developed settings makes it difficult to recruit the qualified health professionals into research. Hence it is better to equip the students so that at the time of qualifying they are conversant with various aspects of research methodology. Studies report that participation in undergraduate medical research motivates students to pursue further research ${ }^{33-34}$. Ability to conduct research is an important skill for the academic and professional advancement of an individual ${ }^{35}$. Research methodology courses at the undergraduate level will be helpful in sensitizing medical students to research. An American study strongly suggests that student research increases interest in an academic career and stimulates additional research ${ }^{36}$. Frishman in his paper explains that research experience will improve the skill of students in searching and critically appraising medical literature which will enhance the ability for independent learning ${ }^{37}$. It would be helpful in making students aware of the health problems of the community and country. Appropriate research training for students should lead to a change in research related practices over time ${ }^{35}$. For the general population to benefit from new locally developed practices there is a need to promote research as a culture among health professionals $^{32}$. In Germany, $28 \%$ of publications from a particular institution are based on student research ${ }^{38}$. One of the questions raised is whether the research projects deprive the student time that could be used for didactic training.

\section{Guideline for implementation}

WHO, South East Asia Region meeting suggested that "Fieldoriented/field-based research is an important component of the undergraduate training in Community Medicine in all countries. Linking the research activities in community medicine and clinical disciplines was considered a useful approach" ${ }^{15}$. It has been reported that one of the longterm approaches for promoting research in the healthcare professional courses is to target medical students early in their careers ${ }^{39-40}$. A change from traditional curriculum to integrated curriculum may help to implement the research component in medical curriculum. Faculty should be trained in research methodology as in many of the schools where the research component is not included, studies report lack of trained faculty.

All institution and research funding agencies must use a certain portion of their budget for promoting student research. Family Medicine department at the University of Colorado, US provide financial support for student research $^{41}$. In Europe, Norwegian Medical Student Research Programme assist students who want to do research in parallel with their other studies ${ }^{42}$.

In conclusion, research methodology is an important component in the undergraduate medical curriculum and the trend showed that in many countries the component is included in the curriculum or is being planned to be included. Studies showed that the major barrier of including research methods in the curriculum is the time and volume of content in the undergraduate medical curriculum.

\section{References}

1. Suzetta Burrows KM, Joaquin Arriaga, Gediminas Paulaitis,Henry L. Lemkau. Developing an "Evidence-Based Medicine and Use of the Biomedical Literature" component as a longitudinal theme of an outcomes-based medical school curriculum: year 1. J Med Libr Assoc 2003;91(1):3441.

2. World Federation for Medical Education. International standards in medical education: assessment and accreditation of medical schools educational programmes. A WFME position paper. Med Educ 1998; 32: 549-58.

3. Deo MG. Need for research oriented medical education in India. Indian J Med Res 2009; 130: 105-7.

4. Undergraduate Medical Curriculum 2005-2006. School of Medicine and Dentistry, Queen's University Belfast. Available at http://www.qub.ac.uk/cm/med_curr/ handbook.pdf. Accessed on October 3, 2011.

5. Fennimore TF. Structured research activity as a vehicle for fostering reflective Practice among Medical students. JIAMSE 2009; 19 (2S): 7-16.

6. Davis DP, Poste JC, Kelly D. The UCSD research associate program: a recipe for successfully integrating undergraduates with emergency medicine research. J Emerg Med 2005; 28:89-93.

7. Ogunyemi D, Bazargan M, Norris K, Jones-Quaidoo S, Wolf K, Edelstein $\mathrm{R}$ et al. The development of a mandatory medical thesis in an urban medical school. Teach Learn Med 2005; 17:363-369.

8. Solomon SS, Tom SC, Pitchert J, Wasserman D, Powers AC. Impact of medical student research in the development of physician_scientists. J Invest Med 2003; 51: 149-56.

9. Gallin EK, Le Blancq SM. Launching a new Fellowship for Medical Students: the first years of the Doris Duke Clinical Research Fellowship Program. J Invest Med 2005; 53: 73-81.

10. Zorzi A, Rourke J, Kennard M, Peterson M, Miller K. Combined research and clinical learning make rural summer studentship program a successful model. Rural Remote Health 2005; 5:401. 
11. Siemens DR, Punnen S, Wong J, Kanji N. A survey on the attitudes towards research in medical school. BMC Medical Education 2010; 10:4. Available at http://www.biomed central.com/1472-6920/10/4. Accessed on November 1, 2011.

12. Van Eyk HJ, Hooiveld HW, Van Leeuwen TN, Van der Wurff BL, De Craen JM, Dekker FWet al. Scientific output of Dutch medical students. Med Teach. 2010; 32: 231-5.

13. Dekker FW, Halbesma $N$, Zeestraten EA, Esther $M$, Vogelpoel, Blees MT, de Jong PGM. Scientific Training in the Leiden Medical School Preclinical Curriculum to Prepare Students for their Research Projects. JIAMSE 2009;19(2S):26.

14. Dommisse J, Joubert G. Profile of research methodology and statistics training of undergraduate medical students at South African universities. SA Fam Pract. 2009: 158-61.

15. Review of Preventive and Social Medicine / Community Medicine / Community Health Curriculum for Undergraduate Medical Education Report of the Expert Group Meeting SEARO, WHO, New Delhi, India, 27-28 August 2009. Available at http://www.searo.who.int/LinkFiles/Reports_SEA-HSD327.pdf. Accessed on November 1, 2011.

16. Aslam F, Shakir M, Qayyum MA. Why medical students are crucial to the future of research in South Asia. PLOS Medicine 2005; 2(11):e322.

17. Soudarssanane MB, Rotti SB, Roy G, Srinivasa DK. Research as a tool for the teaching of epidemiology. World Health Forum 1994;15:48-50.

18. Chaturvedi S, Aggarwal OP. Training interns in population-based research: learners' feedback from 13 consecutive batches from a medical school in India. Med Educ. 2001; 35:585-9.

19. Chaturvedi S, Aggarwal OP Training interns in population-based research: Learners' feedback from 13 consecutive batches from a medical school in India. Med Educ 2001; 35: 585-9.

20. Deo MG. Undergraduate medical students' research in India. J Postgrad Med 2008; 54(3): 176-9.

21. ICMR Short term studentships 2008. Available at: http://www.icmr.nic.in/ short.htm, accessed on November 1, 2011.

22. Bangash MA. Pragmatic Solutions for Problems in the Undergraduate Medical Programmes in Pakistan available at http://www.jpma.org.pk/PdfDownload/2317. pdf accessed on October 31, 2011.
23. Hale C. Community-based learning: an experience. In Adhikari RK, Jayawickramarajah PT (eds.) Essentials of Medical Education. Health Learning Materials Centre, Kathmandu: 1996.

24. Banerjee I, Jauhari CA, Johorey CA, Gyawali S, Saha A. Student's Accreditation of integrated Medical Education in Nepal. Asian Journal of Medical Sciences 2011;2 (1): 49-52.

25. Banerjee I, Jauhari A C, Bista D, Johorey A C, Roy B , Sathian B. Medical Students View about the Integrated MBBS Course: A Questionnaire Based Cross-sectional Survey from a Medical College of Kathmandu Valley. Nepal Journal of Epidemiology 2011;1(3): 95-100.

26. Roy B, Banerjee I, Sathian B, Mondal M, Kumar SS, Saha CG. Attitude of Basic Science Medical Students towards Medicine and Surgery Post Graduation: A Questionnaire based Cross-sectional Study from Western Region of Nepal. Nepal Journal of Epidemiology 2010; 1(4):126-34.

27. Azila NMA, Sim SM. The status of problem-based learning in the medical schools in Malaysia. J Med Educ (Taiwan) 2005;9:121-30.

28. Azila NMA. Preparing for and managing change: Some thoughts for curriculum planners and implementers. Med J Malaysia 2002; 57:52-7.

29. Abdulrahman KA. The current status of medical education in the Gulf Cooperation council countries. Ann Saudi Med 2008; 28(2): 83-8.

30. Hamdy H, Telmesani AW, Al Wardy N, Abdel-Khalek KN, Carruthers G, Hassan F, et al. Undergraduate medical education in the Gulf Cooperation Council: A multicountries study (Part 1). Medical Teacher 2010; 32: 219-24.

31. Diez C, Arkenau C, Meyer-Wentrup F. The German medical dissertation-Time to change? Acad Med 2000; 75: 861-3.

32. Munabi G, Katabira E. T, Konde-Lule J. Early undergraduate research experience at Makerere University Faculty of Medicine: a tool for promoting medical research. African Health Sciences 2006; 6(3): 182-6.

33. Bierer B, Chen HC. How to measure success: the impact of scholarly concentrations on students _ a literature review. Acad Med 2010; 85: 438-52.

34. Jacobs CD, Cross PC. The value of medical student research: the experience at Standford University School of Medicine.Med Educ. 2005; 29: 342-6.

35. David A. Katerndahl MP, Anne C. Larme. Cultural (r)evolution: Developing a research culture in family 
medicine. Commentary fam med 2002; 34(8):616-8.

36. Solomon SS, Tom SC, Pichert J, Wasserman D, Powers AC. Impact of medical student research in the development of physicianscientists. J investing Med 2003; 51:149-56.

37. Frishman WH. Student research projects and theses: should they be a requirement for medical school graduation? Heart Dis. 2001; 3:140-4.

38. Cursiefen C, Alteenbas A. Contribution of medical student research to the Medlineindexed publications of a German medical school. Med Educ 1998; 32:439-40.

39. Segal S, Lloyd T, Houts PS, Stillman PL, Jungas RL, Greer RB. The association between students' research involvement in medical school and their postgraduate medical activities. Acad Med. 1990; 65: 530-3.

40. Reinders JJ, Kropmans TJ, Cohen-Schotanus J. Extracurricular research experience of medical students and their scientifi c output after graduation. Med Educ 2005; 39 : 237.

41. Gonzales AO, Westfall J, Barley GE. Promoting medical student involvement in primary care research. Fam Med 1998; 30:113-6.

42. Steiner H, Breivik J, Siebke M, Tommeras K, Figenschau $\mathrm{K}$, Hansen JB. Evaluation of the medical student research programme in Norwegian medical schools. A survey of students and supervisors. BMC Med Ed 2009; 9: 43.

\begin{tabular}{|l|l|}
\hline \multicolumn{2}{|c|}{ Article Information } \\
\hline \multicolumn{2}{|c|}{ Article history } \\
\hline Received & 10 August 2012 \\
Received in revised form & 15 September 2012 \\
Accepted & 20 September 2012 \\
\hline
\end{tabular}

